\title{
Cytogenetic and molecular study of four couples with multiple trisomy 21 pregnancies
}

\author{
R owena S James ${ }^{1}$, Katrina E llis ${ }^{1}$, D orothy Pettay ${ }^{2}$ and Patricia A Jacobs ${ }^{1}$ \\ ${ }^{1}$ Wessex R egional G enetics L aboratory, Salisbury D istrict H ospital, Wiltshire, UK \\ ${ }^{2}$ D ivision of M edical G enetics, D epartment of Pediatrics, E mory U niversity School of M edicine, A tlanta, USA
}

\begin{abstract}
We studied four families each with three trisomy 21 conceptions. In two of the families the trisomy 21 conceptions all occurred when the mothers were under 35 years of age and in the other two families they all occurred when the mothers were over 35 years of age. Cytogenetic studies showed low level mosaic trisomy 21 in the two younger mothers, but not in the two older. In the three families tested using molecular techniques the results were consistent with the additional chromosome 21 in the trisomic conceptuses being maternally derived. Novel alleles were detected in the trisomic offspring of one of the younger mothers, demonstrating that the mother had been conceived as a trisomy with three different chromosomes 21 . Therefore the multiple trisomy 21 pregnancies in the two younger mothers resulted from maternal trisomy 21 mosaicism, but may have been due to chance in the older mothers.
\end{abstract}

Keywords: Down syndrome; trisomy 21; chromosomal mosaicism

\section{Introduction}

Trisomy 21 occurs in $0.45 \%$ of all clinically recognised pregnancies ${ }^{1}$ and the recurrence risk of trisomy 21 in a family with an affected child is said to be $1-2 \%{ }^{2}$ However, there has been a number of families described with multiple trisomy 21 conceptions. ${ }^{3-10}$ It has been suggested that in some families with multiple trisomy 21 conceptions, a genetic predisposition to nondisjunction of chromosome 21 may have been unmasked. However, a study of 22 families with recurrent trisomy 21 failed to identify any evidence for such a predisposition. ${ }^{9}$ The only well established risk factors for trisomy 21 conceptions are parental mosaicism for a trisomy 21 cell line, and increased maternal

Correspondence: Prof. P A Jacobs, Wessex R egional G enetics Laboratory, Salisbury District Hospital, Salisbury, Wilts. SP28BJ UK. Tel: +44 1722336262 x4080; Fax: +44 1722 338095

R eceived 5 A ugust 1997; revised 140 ctober 1997; accepted 24 N ovember 1997 age. ${ }^{1,8}$ E stimates of the frequency of parental mosaicism which is detectable cytogenetically range from $2.7 \%-4.3 \%{ }^{6}{ }^{6} \mathrm{H}$ owever, the karyotype demonstrated in blood or skin tissues does not necessarily represent the chromosome constitution of the germline cells. Nielsen et $\mathrm{al}^{7}$ described a female with six confirmed trisomy 21 conceptions. No trisomic cell line was found during extensive examination of blood and skin tissue, but cytogenetic analysis of ovarian tissue demonstrated a trisomy 21 cell line in 12/79 cells. ${ }^{7}$ The recent availability of highly polymorphic microsatellite sequences has made it possible to reveal the trisomic constitution of a parental germline by the identification of an allele in the trisomic offspring which is not seen in the somatic tissues of either parent. ${ }^{9}$

Prenatal diagnosis has been undertaken in our laboratory since 1972 . During this 25 -year period we have ascertained nine women who have had more than one trisomy 21 pregnancy; five women have had two such pregnancies and four women have had three. In no 
family was there any recognised case of Down syndrome outside the proband sibship. The women fell into two groups on the basis of maternal age (Table 1); in one group of three women all the trisomy 21 conceptions occurred when the mothers were under 35 years of age and in the other group of six women all the trisomy 21 conceptions occurred when the mothers were over 35 years of age.

The occurrence of three trisomy 21 conceptions, especially under the age of 35 as was the case in two of our patients, suggested that they might well be the result of an underlying biological mechanism rather than an unfortunate play of chance. The four couples who had three trisomy 21 pregnancies were therefore investigated for the presence of mosaicism. Where possible this was done (i) by determining the parental origin of the additional chromosome 21 , (ii) by scoring a minimum of 100 cells from both blood and skin fibroblasts in the parent who had contributed the additional chromosome, and (iii) by studying the inheritance of a number of chromosome 21 DNA polymorphisms in the parents and trisomy 21 conceptuses to see whether we could detect one or more alleles in the trisomy 21 offspring that were absent from the somatic tissues of the parents. The presence of such alleles would provide direct evidence for trisomy 21 mosaicism involving the germ cells of the parent who had contributed the additional chromosome 21 .

\section{Materials and Methods}

\section{Families}

The pedigrees of the four families are shown in Figure 1.

Family $F$ was ascertained in 1978 because of a Down syndrome male born when the mother was aged 23 . Three subsequent pregnancies were monitored by prenatal diagnosis; the first conceived when the mother was 24 was a male

Table 1 Maternal ages at time of conception of +21 pregnancies

\begin{tabular}{|c|c|c|c|c|c|}
\hline \multirow[b]{2}{*}{ Family } & \multirow{2}{*}{$\begin{array}{l}\text { No. of } \\
\text { pregnancies }\end{array}$} & \multirow{2}{*}{$\begin{array}{l}\text { No. of }+21 \\
\text { pregnancies }\end{array}$} & \multicolumn{3}{|c|}{$\begin{array}{l}M \text { aternal age }(y) \\
\text { at conception of }+21\end{array}$} \\
\hline & & & 1 & 2 & 3 \\
\hline W & 6 & 3 & 37 & 40 & 43 \\
\hline$E G$ & 3 & 3 & 36 & 40 & 40 \\
\hline $\mathrm{D}$ & $? 2$ & 2 & 38 & 38 & \\
\hline $\mathrm{E}$ & 4 & 3 & 28 & 32 & 33 \\
\hline $\mathrm{F}$ & 4 & 3 & 23 & 24 & 29 \\
\hline $\mathrm{H}$ & 3 & 2 & 26 & 28 & \\
\hline $\mathrm{N}$ & 3 & 2 & 15 & 28 & \\
\hline PE & ?2 & 2 & 23 & 30 & \\
\hline PU & ?2 & 2 & 26 & 29 & \\
\hline
\end{tabular}

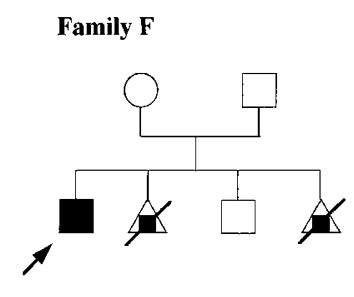

Family W

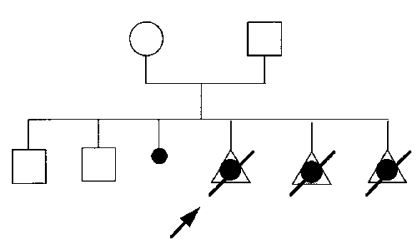

Family EG

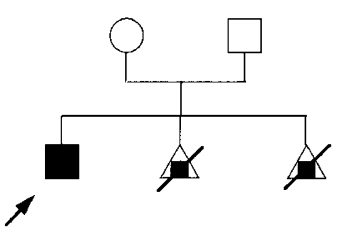

Family E

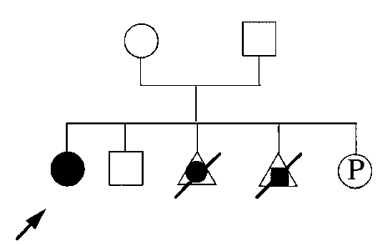

Figure 1 Pedigrees of families F, W, E and EG.

with trisomy 21 , the second conceived when the mother was 24 was a normal male, while the third, conceived when the mother was 29 was a male with trisomy 21.

Family W was ascertained in 1990 because of prenatal diagnosis of a female foetus with trisomy 21 conceived when the mother was aged 37. Previously she had had two normal male children and a spontaneous abortion. Prenatal diagnosis was carried out in two subsequent pregnancies, when the mother was aged 40 and 43 . B oth showed a female foetus with trisomy 21.

Family E was ascertained in 1991 through a female child with Down syndrome born when the mother was aged 28. Two years later she had a chromosomally normal male child, followed by prenatal diagnosis of a female foetus with trisomy 21 when she was aged 32 and a male foetus with trisomy 21 when she was aged 33 . She is currently five months pregnant and carrying a foetus with a $46, \mathrm{XX}$ chromosome constitution.

Family EG was ascertained in 1992 through a male child with trisomy 21 born when the mother was 36 years old. Two subsequent pregnancies, conceived when the mother was aged 40 , were both diagnosed prenatally as male foetuses with trisomy 21.

\section{Molecular Analysis}

DNA was extracted from peripheral blood, amniocytes, chorionic villi and foetal tissues using a salt precipitation technique. ${ }^{11}$ In order to determine the parental origin of the additional chromosome the inheritance of polymorphic microsatellite DNA markers located along the length of chromosome 21 was studied. The loci tested, in order from 21pter to 21qter were: D21S369, D 21S215, D 21S258, D 21S120, D 21S13, D 21S1， D 21S11，D21S210，D 21S82, D 21S213， D 21S223, IFNAR* <>*D21S1910, D 21S55, D 21S156, H M G 14, D 21S113, D 21S171, D 21S112, CO L 6A $1^{12}$ [H assold T, personal communication 1997] (* Order of these two markers uncertain). Loci D21S13, D21S1, D 21S82, D 21S55, D 21S113, D 21S112 and COL6A 1 were tested by Southern analysis. The remaining markers were tested using standard PCR techniques. ${ }^{13}$ Probes and primer sequences used are available on the $G$ enome Data B ase.

In order to determine the cell division at which the nondisjunctional event occurred, in the absence of an informative 
centromeric marker the most proximal $21 \mathrm{q}$ markers, D 21S369, D 21S215, D 21S258 and D21S120 were studied. Informative loci were heterozygous in the parent of origin, and heterozygosity was either retained in the trisomic offspring, indicating an error during meiosis I (MI) or reduced to homozygosity in the trisomic offspring, indicating an error either during meiosis II (MII) or during post-zygotic mitosis (PZM). MII and PZM errors could be distinguished by the reduction to homozygosity of all informative markers along the length of the chromosome in cases of mitotic nondisjunction.

\section{Cytogenetic Analysis}

Cytogenetic studies of blood, skin fibroblasts, amniocytes and chorionic villi were done using standard techniques. All prenatally diagnosed trisomy 21 pregnancies were terminated and the results confirmed on fibroblasts grown from foetal tissues.

\section{Results}

\section{Molecular Analysis}

$M$ olecular studies could be undertaken in only three of the four families as Family $F$ was ascertained in 1978 and no material was available for DNA extraction. R esults of molecular analyses of families W, E and EG are in Table 2, and examples shown in Figure 2.

In family $\mathrm{W}$ the maternal origin of the additional chromosome 21 was demonstrated by the presence of

Table 2 M olecular results of three families with three trisomy 21 conceptions

\begin{tabular}{|c|c|c|c|c|c|c|c|c|}
\hline L ocus & Probe & Enzyme & L ocation & Father & Mother & Proband 1 & Proband 2 & Proband 3 \\
\hline $\begin{array}{l}\text { Family W } \\
\text { D 21S369 } \\
\text { D 21S215 } \\
\text { D 21S258 } \\
\text { D 21S120 } \\
\text { D 21S13 } \\
\text { D 21S1 } \\
\text { D 21S11 } \\
\text { D 21S210 } \\
\text { D 21S82 } \\
\text { D 21S213 } \\
\text { D 21S223 } \\
\text { D 21S167 } \\
\text { D 21S55 } \\
\text { D 21S156 } \\
\text { H M G 14 } \\
\text { D 21S113 } \\
\text { D 21S171 } \\
\text { D 21S112 } \\
\text { C } 0 \text { L 6A 1 }\end{array}$ & $\begin{array}{l}\text { Fr-8-77 } \\
\text { G TO } 5 \\
\text { pPW 518-1R } \\
\text { pM CT } 15 \text { Taq1 } \\
\text { pN T 427-4/14/15 } \\
\text { pM L 18 }\end{array}$ & $\begin{array}{l}\text { BamH } 1 \\
\text { Taq1 }\end{array}$ & $\begin{array}{l}21 \text { cen-q11 } \\
21 \text { cen-q11 } \\
21 \text { cen-q11 } \\
21 q 11 \\
21 q 11 \\
21 q 21 \\
21 q 21 \\
21 q 21-q 22.1 \\
21 q 22.1-q t e r \\
21 q 21-q 22.1\end{array}$ & $\begin{array}{l}1,1 \\
1,1 \\
2,3 \\
A, A / 2,2 \\
1,1 \\
1,2 \\
1,2 \\
1,2 \\
2,2 \\
\text { A ,A } \\
1,2 \\
2,2 \\
\text { A,B } \\
\text { A,B } \\
1,3 \\
\text { A,B } \\
\text { 2,3 } \\
\text { A,A /A,B } \\
\text { 1,2/A ,A }\end{array}$ & $\begin{array}{l}1,2 \\
1,1 \\
1,3 \\
A, B / 1,2 \\
1,2 \\
1,2 \\
1,3 \\
1,2 \\
2,2 \\
B, B \\
2,3 \\
1,2 \\
A, A \\
C, D \\
2,4 \\
A, A \\
1,2 \\
\text { A,B /A,C } \\
\text { 1,2/B,B }\end{array}$ & $\begin{array}{l}N / T \\
1,1,1 \\
N / T \\
A, A, B \\
1,1,2 \\
1,1,2 \\
N / T \\
N / T \\
2,2,2 \\
A, B, B \\
N / T \\
N / T \\
A, A, B \\
A, C, D \\
N / T \\
A, A, B \\
N / T \\
A, A, B / A, A, C \\
1,1,2 / A, B, B\end{array}$ & $\begin{array}{l}1,1,2 \\
1,1,1 \\
1,3,3 \\
1,2,2 \\
N / T \\
N / T \\
1,2,3 \\
1,2,2 \\
N / T \\
A, B, B \\
1,2,3 \\
1,2 \\
N / T \\
A, C, D \\
1,2,4 \\
N / T \\
1,2,2 \\
N / T \\
N / T\end{array}$ & $\begin{array}{l}1,1,1 \\
1,1,1 \\
3,3,3 \\
2,2,2 \\
N / T \\
N / T \\
1,1,3 \\
1,1,2 \\
N / T \\
N / T \\
2,2,3 \\
1,2 \\
N / T \\
N / T \\
1,2,4 \\
N / T \\
1,2,2 \\
N / T \\
N / T\end{array}$ \\
\hline $\begin{array}{l}\text { Family E } \\
\text { D 21S369 } \\
\text { D 21S215 } \\
\text { D 21S258 } \\
\text { D 21S120 } \\
\text { D 21S210 } \\
\text { D 21S223 } \\
\text { IFNAR } \\
\text { D 21S1910 } \\
\text { D 21S167 } \\
\text { H M G 14 } \\
\text { D 21S171 }\end{array}$ & & & $\begin{array}{l}21 \text { cen-q11 } \\
21 \text { cen-q11 } \\
21 \text { cen-q11 } \\
21 q 11 \\
21 q 21-q 22.1 \\
21 q 22.1\end{array}$ & $\begin{array}{l}2,2 \\
2,2 \\
1,3 \\
2,3 \\
2,2 \\
3,4 \\
1,2 \\
1,3 \\
2,2 \\
2,3 \\
2,2\end{array}$ & $\begin{array}{l}1,2 \\
1,2 \\
2,2 \\
1,1 \\
1,2 \\
1,2 \\
2,4 \\
2,4 \\
1,2 \\
1,4 \\
1,3\end{array}$ & $\begin{array}{l}1,1,2 \\
1,1,2 \\
1,2 \\
1,1,3 \\
2,2,2 \\
2,2,4 \\
1,2,3^{*} \\
1,4,5^{*} \\
1,1,2 \\
1,3,4 \\
1,2,3\end{array}$ & $\begin{array}{l}1,1,2 \\
1,1,2 \\
1,2,2 \\
1,1,3 \\
2,2,2 \\
2,2,4 \\
1,3^{*}, 4 \\
1,2,5^{*} \\
1,2 \\
1,1,2 \\
2,3\end{array}$ & $\begin{array}{l}1,1,2 \\
1,1,2 \\
1,2 \\
2,2,2 \\
2,3 \\
2,2,3^{*} \\
3,4,5^{*} \\
1,2 \\
1,3,4 \\
1,2\end{array}$ \\
\hline $\begin{array}{l}\text { Family EG } \\
\text { D 21S369 } \\
\text { D 21S215 } \\
\text { D 21S210 } \\
\text { D 21S223 } \\
\text { IF A R } \\
\text { D 21S1910 } \\
\text { H M G } 14\end{array}$ & & & $\begin{array}{l}21 \text { cen-q11 } \\
21 \text { cen-q11 } \\
21 q 21-q 22.1\end{array}$ & $\begin{array}{l}1,3 \\
1,2 \\
2,2 \\
1,2 \\
1,3 \\
1,4 \\
3,4\end{array}$ & $\begin{array}{l}1,2 \\
3,4 \\
1,3 \\
1,1 \\
1,2 \\
2,3 \\
1,2\end{array}$ & $\begin{array}{l}1,1,2 \\
1,3,4 \\
1,2,3 \\
\text { N T } \\
1,1,2 \\
1,2,3 \\
1,2,3\end{array}$ & $\begin{array}{l}1,1,2 \\
1,3,4 \\
1,2,3 \\
1,1,2 \\
1,2,3 \\
2,3,4 \\
1,2,4\end{array}$ & $\begin{array}{l}1,1,2 \\
1,3,4 \\
1,2,3 \\
\mathrm{NT} \\
1,2,3 \\
2,3,4 \\
1,2,4\end{array}$ \\
\hline
\end{tabular}

$*=$ denotes a novel allele not found in either parent. 
two maternally derived alleles at loci D 215156 (probands 1 and 2) and HMG 14 (probands 2 and 3). There was also increased dosage of a maternal allele at D 21 S213 (probands 1 and 2) and CO L 6A 1 (proband 1). In this family probands 1 and 2 resulted from errors during maternal $\mathrm{MI}$, since the most proximal informative markers tested retained their heterozygosity in the trisomic offspring. In proband 3, however, the error must have occurred during MII as heterozygosity is reduced to homozygosity in markers close to the centromere but is retained in the more distal markers.

In family EG the maternal origin of the additional chromosome 21 was demonstrated by the presence of a second maternally derived allele at D 21S215, D 21S210, D $21 S 1910$ and H M G 14 in all three trisomic offspring. In this family at all loci where the mother is heterozygous, the heterozygosity is retained in all the trisomic offspring. This suggests that all three offspring resulted from a reduction or absence of recombination with subsequent non-disjunction at mat MI.

In family $E$ all three trisomic offspring had three different alleles at locus D21S1910. O ne of the alleles was present in the mother and one in the father, but the 3rd allele was apparently novel and was not detectable in either parent (Figure 3). A t locus IF NA R trisomies 1 and 2 had three different alleles, one from each parent and one novel, while the novel allele was also detected in the third trisomy, in association with two copies of an allele detected in both parents. A t other loci there was evidence for an additional allele that was also detected in the mother, suggesting that the extra chromosome was maternally inherited: HMG 14 (probands 1 and 3) and D 21S171 (proband 1). There was increased intensity of an allele also present in the mother at D 21S369 and D $21 S 215$ (probands 1, 2 and 3); D $21 S 258$ (proband 2); D $21 S 120$ (probands 1 and 2); D $21 S 223$ (probands 1 and 2); D 21S167 (proband 1) and HMG 14 (proband 2).

\section{Cytogenetic Analysis}

R esults of cytogenetic analysis of parental blood and skin samples are in Table 3. In two of the mothers ( $F$ and $E$ ) a minor cell line with an additional chromosome 21 was identified. In family $\mathrm{F} 3 / 82$ cells from maternal blood showed trisomy 21 . In family E 1/170 cells from the mother's blood and 3/100 cells from skin fibroblasts showed trisomy 21. In families W and EG there was no evidence of parental trisomy 21 mosaicism in 100 cells examined from both peripheral blood and skin (mother and father $E G$, and mother $W$ ) or from peripheral blood alone (father W).
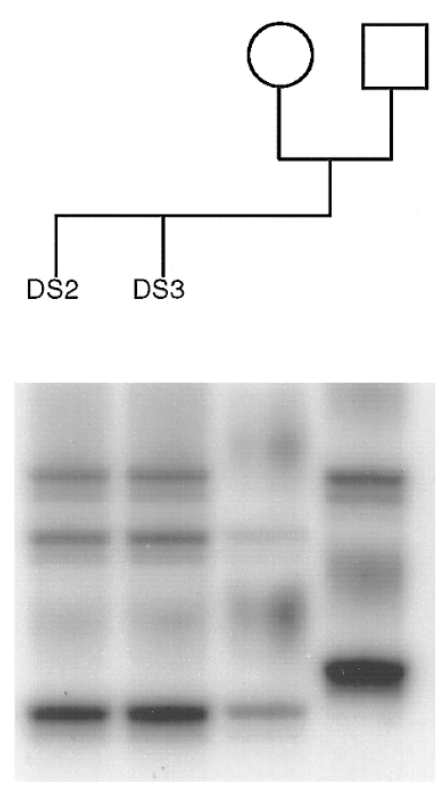

FAMILY W HMG14
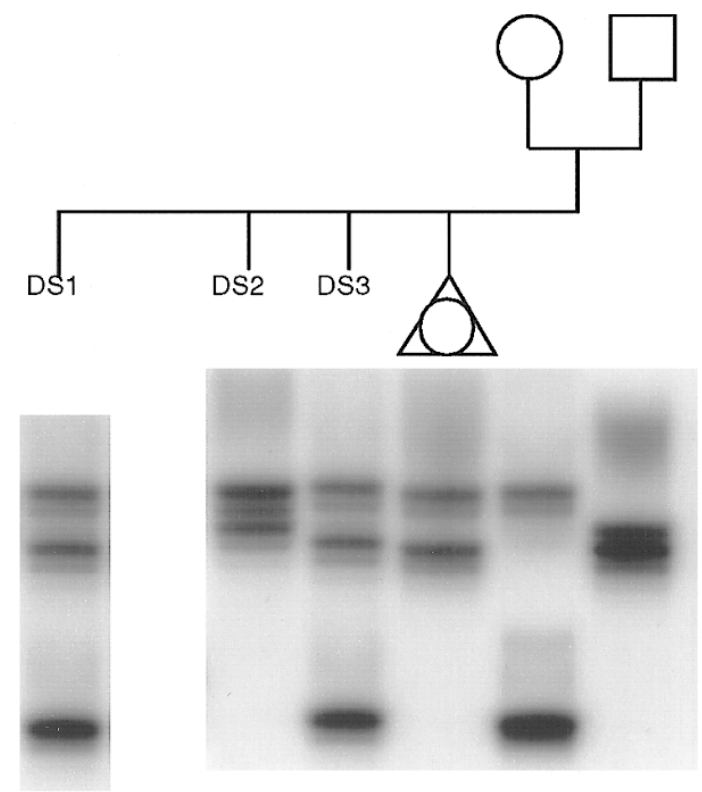

FAMILY E HMG14
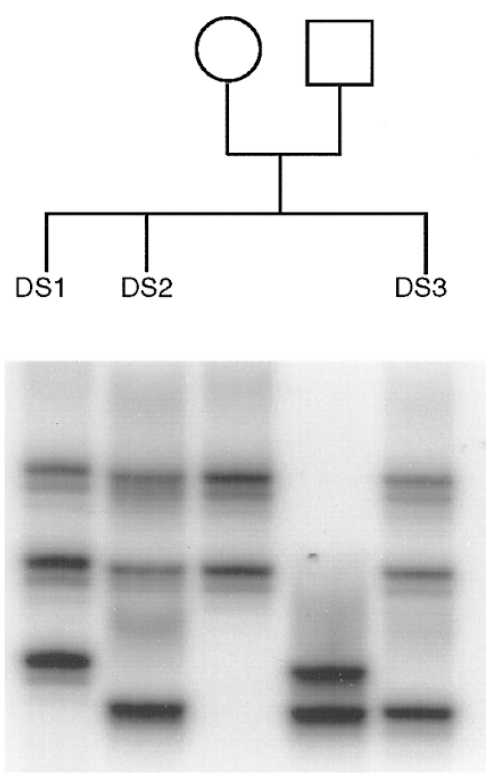

FAMILY EG HMG14

Figure 2 A utoradiographs of microsatellite repeat analysis using primers at the H M G locus to demonstrate the parental origin of the additional chromosome 21 in the trisomic (DS) offspring of families W, E and E G Family. W: Father 1,3; M other 2,4; D S2 1,2,4; D S3 1,2,4. Family E: Father 2,3; M other 1,4; DS1 1,3,4; D S2 1,1,2; D S3 1,3,4; N ormal 46,XX sib 1,3. Family E G: Father 3,4; M other 1,2; DS1 1,2,3; DS2 1,2,4; DS3 1,2,4. 

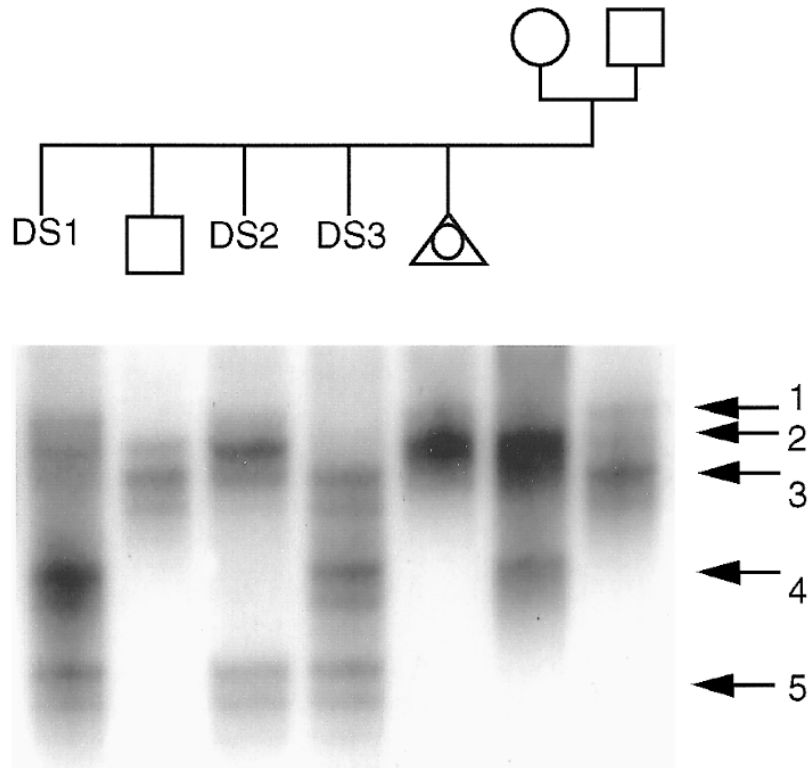

Figure 3 Autoradiograph of microsatellite repeat analysis using primers at D21S1910 to demonstrate the presence of 'novel' allele 5 in all Down syndrome offspring in family $E$. Father 1,3; M other 2,4; D S1 1,4,5; N ormal 46,XY sib 2,3; D S2 1,2,5; D S3 3,4,5; Normal 46,XX sib 1,2.

\section{Discussion}

We have identified four families each with three trisomy 21 conceptions, and have attempted to define the mechanisms resulting in trisomy 21 in each case. Previous studies of multiple D own syndrome conceptions have demonstrated that parental mosaicism for a trisomy 21 cell line is causal in a proportion of cases, for example in references. ${ }^{6,8 \& 9} \mathrm{~A} s$ expected, in such cases parental age at conception of the trisomic offspring does not appear to be increased over the age at conception of normal offspring. In the absence of parental mosaicism for a trisomy 21 cell line, the trisomic pregnancies may have arisen either by a nondisjunctional error during meiosis, or by a post-zygotic mitotic error resulting in the gain of a chromosome 21. The majority of trisomy 21 conceptions has been shown to be the result of errors during maternal $\mathrm{MI}^{12}$ and associated with an increased maternal age at conception.

In two of the four families studied (families $F$ and $E$ ) the maternal age was less than 35 years at the time of conception of each trisomic pregnancy. Cytogenetic analysis of parental bloods, and skin where available, demonstrated low level mosaicism for trisomy 21 in these two mothers (Table 3). Maternal mosaicism for trisomy 21 is therefore the cause of the multiple D own syndrome offspring in these families. These mothers may themselves have been conceived either as trisomy 21 with the subsequent very early mitotic loss of one of the chromosome 21 homologues, or as normal conceptions with the subsequent gain of a chromosome 21 resulting from a post-zygotic mitotic error. In both cases, the degree of mosaicism was very low, and there was no Down syndrome phenotype. U nfortunately we were not able to ascertain parental ages at the time of conception of the mothers. In family $F$ there was no material available for molecular studies, however, in family E, molecular studies demonstrated the presence in all three trisomic offspring of alleles which were not detectable in the maternal DNA extracted from somatic tissues (Table 2, loci IFNAR and D21S1910). These 'novel' alleles indicate that within the maternal germline there must be a trisomy 21 cell line with three different chromosomes 21. This mother, therefore, originated as a trisomy 21 conceptus after a nondisjunctional meiotic event, with the subsequent loss of one chromosome 21 homologue resulting in a mosaic karyotype. Three similar patients have been reported by Pangalos et al, ${ }^{9}$ one a cytogenetically confirmed mosaic mother of two Down syndrome offspring, and two mothers in whom mosaicism had not been confirmed cytogenetically. The detection of 'novel' alleles in the trisomics does confirm the presence of parental mosaicism as the cause of recurrent trisomy 21 . If there had been no cytogenetic evidence of maternal mosaicism, the parental origin of the additional chromosome 21 could not have been confirmed since the 'novel' alleles could have been derived from either parent. However, the presence in the trisomics of additional

Table 3 Parental karyotypes in the four families with three +21 pregnancies

\begin{tabular}{llllll}
\hline & Maternal karyotype & & & \multicolumn{2}{l}{ Paternal karyotype } \\
\cline { 2 - 3 } Family & Blood & Skin fibroblasts & & & Blood \\
\hline F & $46, X X,[79] / 47, X X,+21,[3]$ & $N T$ & $46, X Y$ & Skin \\
W & $46, X X[100]$ & $46, X X[100]$ & & $46, X Y[100]$ & $N T$ \\
E & $46, X X[169] / 47, X X+21[1]$ & $46, X X[97] / 47, X X+21[3]$ & & $46, X Y[100]$ & $46, X Y[2]$ \\
E G & $46, X X[96] / 45, X[3] / 47, X X X[1]]^{a}$ & $46, X X[100]$ & & $46, X Y[100]$ & $46, X Y[100]$ \\
\hline
\end{tabular}

aC ells that have an aberrant number of $X$ chromosomes are considered to be the result of aging. 
alleles shared with the mother is suggestive of a maternal origin.

The parents and cell divisions of origin and the reduction in recombination seen in the probands born to the two older mothers are very similar to those seen in a large series of singleton D own syndrome pregnancies. $^{12}$ Whilst it is impossible to exclude a genetic predisposition to trisomy 21 non-disjunction in these women, it is an unattractive suggestion because there is no convincing evidence for a genetic predisposition to non-disjunction in our species, either for a specific chromosome ${ }^{9}$ or for non-disjunction in general. ${ }^{14}$ It therefore seems reasonable to consider that the three trisomic probands in the older women arose by chance.

If the data from our four families are added to those of Pangalos et al, ${ }^{9}$ there is a total of nine sibships with multiple trisomy 21 pregnancies born to mothers aged 35 or less, and eight sibships with multiple trisomy 21 pregnancies born to mothers aged 36 or more. In the young maternal age group six of the nine were found to have a parent who was a trisomy 21 mosaic, while in the older age group only one of the eight had a mosaic parent. Thus gonadal mosaicism may be the explanation for the great majority of women who have more than one trisomy pregnancy at a young age, while multiple Down syndrome pregnancies in older women are more likely to be due to chance.

\section{Acknowledgements}

The work of R SJ and PA J is supported by the Wellcome Trust, and that of DP by grant NIH PO 1 HD 32111. The authors thank Tracy Wilkinson, A ndrew Sharp, Fiona Long, John Crolla, Terry $\mathrm{H}$ assold and Stephanie Sherman for their assistance and helpful discussion.

\section{References}

$1 \mathrm{H}$ assold TJ, Jacobs PA : Trisomy in man. A nn Rev Genet 1984; 18: 69-97.

2 Daniel A, Stewart L, Savill T et al: Prenatal diagnosis in 3000 women for chromosome, $\mathrm{X}$-linked and metabolic disorders. A m J M ed G enet 1982; 11: 61-75.

$3 \mathrm{~K}$ affe $\mathrm{S}, \mathrm{H}$ su LY F, H irschhorn K: Trisomy 21 mosaicism in a woman with two children with trisomy 21 Down's syndrome. J Med G enet 1974; 11 378-381.

4 O suna A. M oreno A : R egular G 21-trisomy in 3 sibs from mother with trisomy 21 mosaicism. J M ed G enet 1977; 14: 286-287.

$5 \mathrm{H}$ arris DJ, Begleiter $\mathrm{ML}$, Chamberlin J, Hankins L, Magenis RE :Parental trisomy 21 mosaicism. A m J H um Genet 1982; 34: 125-133.

6 U chida IA, Freeman V CP: Trisomy 21 D own syndrome. $\mathrm{H}$ um $\mathrm{G}$ enet 1985; 70: 246-248.

$7 \mathrm{~N}$ ielsen K G, Poulsen H, M ikkelsen M, Steuber E : M ultiple recurrence of trisomy 21 Down syndrome.Hum Genet 1988; 78: 103-105.

8 Sachs ES, Jahoda M GJ, LoS FJ, Pijpers L, W ladimiroff JW:Trisomy 21 mosaicism in gonads with unexpectedly high recurrence risks. Am J Med Genet 1990; 7 (suppl): 186-188.

9 Pangalos CG, Talbot CC Jr, Lewis JG et al: DNA polymorphism analysis in families with recurrence of free trisomy 21. A m J H um G enet 1992; 51: 1015-1027.

$10 \mathrm{~K}$ rishna M urthy DS, Farag TI: R ecurrent regular trisomy21 in two Bedouin families. Ann Génét 1995; 38, 4 217-224.

11 Miller SA, Dykes DD, Polesky HF : A simple salting out procedure for extracting DNA from human nucleated cells. Nucleic A cids Res 1988; 16: 1215.

12 Sherman SL, Petersen MB, Freeman SB et al: Nondisjunction of chromosome 21 in maternal meiosis I: evidence for a maternal age-dependent mechanism involving reduced recombination. $\mathrm{H}$ um $\mathrm{M}$ ol $\mathrm{G}$ enet 1994; 3: 1529-1535.

13 Hudson TJ, Engelstein M, Lee MK et al: I solation and chromosomal assignment of 100 highly informative human simple sequence repeat polymorphisms. G enomics 1992; 13: 622-629.

$14 \mathrm{H}$ assold $\mathrm{T}$ : A cytogenetic study of repeated spontaneous abortions. A m J H um G enet 1980; 32: 723-730. 